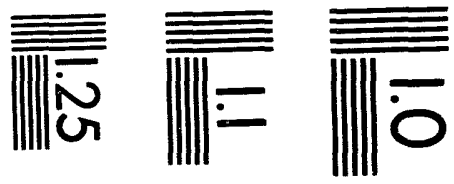

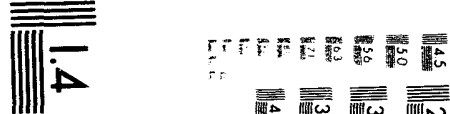

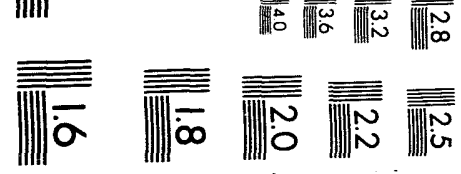



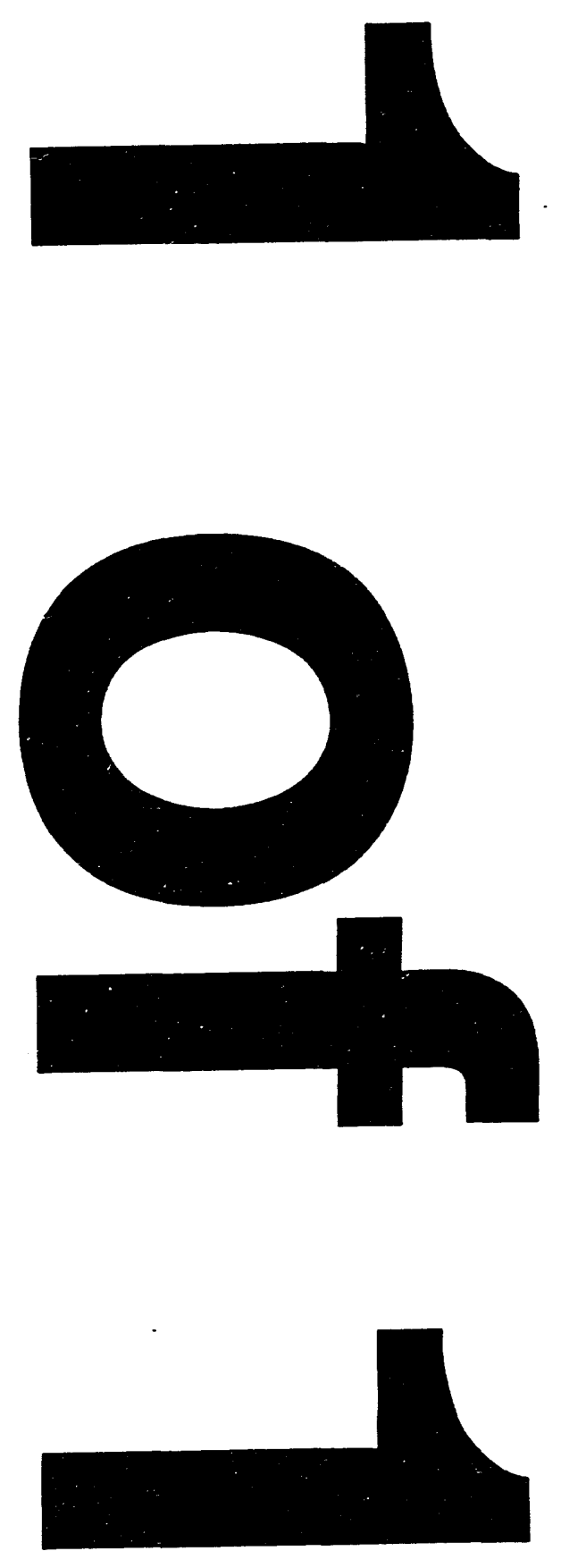
Space debris removal using a high-power ground-based laser*

\title{
David K. Monroe
}

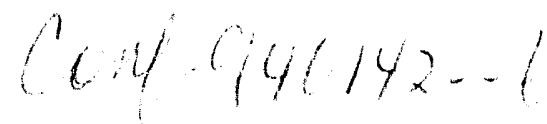

Sandia INational Laboratories

Albuquerque, NM 87185-0744

\begin{abstract}
The feasibility and practicality of using a ground-based laser (GBL) to remove artificial space debris is examined. Physical constraints indicate that a reactor-pumped laser (RPL) may be best suited for this mission, because of its capabilities for multimegawatt output, long run-times, and near-diffraction-limited initial beams. Simulations of a laser-powered debris removal system indicate that a 5-MW RPL with a 10-meter-diameter beam director and adaptive optics capabilities can deorbit $1-\mathrm{kg}$ debris from space station altitudes. Larger debris can be deorbited or transferred to safer orbits after multiple laser engagements. A ground-based laser system may be the only realistic way to access and remove some 10,000 separate objects, having velocities in the neighborhood of $7 \mathrm{~km} / \mathrm{sec}$, and being spatially distributed over some $10^{10} \mathrm{~km}^{3}$ of space.
\end{abstract}

\section{MITIGATING THE SPACE DEBRIS THREAT}

Hypervelocity collisions with artificial space debris constitute a growing potential threat to space assets in low-earth orbit (LEO). A number of encounters have already occurred, and their frequency is projected to increase in the future. It has been suggested that a debris "population explosion" could occur as collisions between debris objects greatly increase the existing population. ${ }^{1-9}$

Mission planners are concerned that the planned US space station could be temporarily or permanently disabled by space debris impacts. Because of its large total area and its long mission time, the space station is perhaps the most likely potential victim of a serious debris-impact event. It has been estimated that for a 30-year mission duration the probability of a catastrophic loss may be as high as $75 \%$, and catastrophe would be transformed into tragedy if there were personnel onboard at the time. 8,10

Passive debris shieids can offer some protection, and several advanced designs have recently been proposed. These shields are effective against the more probable encounters, those with debris having sizes up to about $1 \mathrm{~cm}$. A drawback to using shields is that they add significantly to total launch weight. For shields designed to protect against debris larger than about $1 \mathrm{~cm}$, this weight penalty would become unacceptable. $1,3,5,9,11,12$

Detection and avoidance have already been used by maneuvering space systems. On three occasions a shuttle has undergone orbital alterations to reduce impact probability. To date, all such operations have been handled from the ground ${ }^{l}$ It has been proposed that space assets be provided with onboard infrared or radar detectors and autonomous control systems to command maneuvers. However, this would imply serious penalties with regard to launch weight, mission duration, and overall system complexity. 6,13

Mechanical debris sweepers have been proposed for removing debris from orbit. These consist of panels to capture debris or sheets of thin materials to reduce debris velocities. To be effective, these sweepers would have to be very large in area, resulting in some degree of awkwardness during deployment and steering. For the panel designs it would also imply large total mass and greater overall cost. Large mass could also result in a significant increase in the existing debris population, if the sweeper encountered a very large article of debris. Both designs would be made very complex, if autonomous detection and maneuvering capabilities were included. ${ }^{7}$

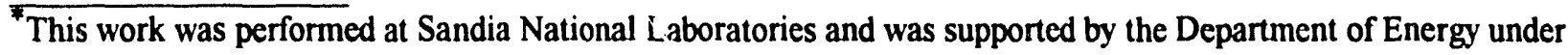
contract DE-AC04-94AL85000.
}

\section{DISCLAIMER}


Space-based, directed-energy systems have been proposed for removing debris from earth orbit. Highly concentrated laserbeam or particle-beam power could be utilized to completely vaporize debris or to perturb debris orbits. However, basing either of these systems in space has all of the serious disadvantages normally associated with high-power space platforms. Examples of these are total system costs, technology requirements, thermal energy rejection, system reliability, maintenance, and resupply requirements. ${ }^{14-16}$

For lasers a practical alternative is to locate the system on the earth's surface, thereby resolving many of the problems associated with space basing. Laser power at an appropriate wavelength could be beamed directly to orbiting debris or could be redirected to the debris by an orbiting mirror. This paper considers debris removal using a GBL without the orbiting mirror option. Any gains to be obtained by including the mirror would be largely offset by launch and maintenance costs, as well as by overall system complexity.

It is proposed that a GBL system can remove debris with masses of the order of $1 \mathrm{~kg}$ froin space station altitudes. The laser performance parameters assumed in this paper are based upon the observed and projected capabilities of the FALCON (Fission Activated Laser CONcept) RPL, ${ }^{\dagger}$ which is a very strong candidate for the laser source. RPL's are capable of providing multimegawatt power levels, long run times, and near-diffraction-limited initial beams, all of which are requirements for this mission. ${ }^{17,18}$

\section{DESIGN PARAMETERS FOR GBL SYSTEM}

The proposed debris-removal system consists of a reactor-pumped GBL and a large steerable beam director (SBD), with an adaptive optics unit (AOU) to provide wavefront-correction capabilities. Figure 1 illustrates these subsystems and their relationships. The system is designed to beam concentrated laser power to orbital altitudes, where it will ablate debris surfaces and generate impulse. The imparted delta-velocity will perturb debris orbits and will cause some articles of dcbris to re-enter the atmosphere.

The FALCON RPL operates in continuous-wave (CW) mode with acceptable efficiencies at a number of wavelengths in the near-infrared. $¥$ One of these, the 1733 -nm line, is particularly attractive because it is not affected very seriously by atmospheric absorption or turbulence. This wavelength is assumed throughout the remainder of this paper. The $\mathrm{CW}$ output of the laser is assigned the nominal value of $5 \mathrm{MW}$, which is sufficient to produce debris surface ablation after atmospheric losses and wavefront corrections. Power levels of this magnitude can be achieved with RPL's like FALCON, ${ }^{\dagger}$ because their outputs are intrinsically scalable. $\$$

The laser beam is optically processed by a beam director having a 10-meter-diameter mirror with adaptive-optics capabilities in the beam train. Mirrors of this size are feasible, as has been demonstrated by the recent installation of the Keck telescope mirror. Adaptive optics techniques are very effective in the near-infrared where distortions due to atmospheric turbulence are minimal. A low-power sensing beam is used to estimate the effects of wavefront distortions, as illustrated in Figure 1. These estimates are then used to generate real-time commands for the mirror, which pre-distorts the wavefronts to compensate for the effects of atmospheric turbulence. ${ }^{19,20}$

Turbulence-distorted beams can be restored to nearly diffraction-limited intensity patterns. The only departure from true diffraction-limited propagation is a residual amount of beam spreading. The Strehl ratio, which is a measure of beam spreading, equals unity for a truly diffraction-limited intensity pattern, and is less than unity for a corrected beam. In this paper the Strehl ratio is assigned the nominal value of $50 \%$. This degree of beam quality is within the capabilities of adaptive optics techniques, as long as the laser beam's angle-off-zenith (AOZ) does not exceed about $60^{\circ}$. This limitation on $\mathrm{AOZ}$ is assumed in this paper. 19,20

F. S. Pickard, "FALCON Reactor-Pumped Laser, Description and Program Overview," internal program report, Sandia National Laboratories (1991).

$\ddagger$ R. J. Lipinski, "FALCON Applications," internal program report, Sandia National Laboratories (April 14, 1992). 


\section{LASER POWER BEAMING DETAILS}

The intensity distribution incident upon the debris surface can be approximated by a Gaussian distribution. (See Figure 2.) In terms of the $\mathrm{AOZ}$ and the radial distance from the central axis of tie beam, the intensity can be represented as follows:

$$
I_{\text {inc }}(Z, r)=I_{\text {inc }}(Z, 0) \exp \left[-(r / r G(Z))^{2}\right] \text {. }
$$

The Gaussian radius, $r_{G}(Z)$, is the half-width of the distribution for an intensity level equal to $\mathrm{e}^{-1}$ times the peak intensity. It is determined by the transmitted wavelength, debris slant range, mirror diameter, and Strehl ratio:

$$
r_{G}(Z)=\left[2 \lambda_{\text {trans }} R_{\text {debris }}(Z)\right] /\left[\pi D_{\text {mirror }} \sqrt{S}\right] \text {. }
$$

The peak intensity, $\mathrm{I}_{\text {inc }}(\mathrm{Z}, 0)$, is the ratio of the total incident power to the area of the Gaussian disk:

$$
\mathrm{I}_{\text {inc }}(\mathrm{Z}, 0)=\mathrm{P}_{\text {inc }}(\mathrm{Z}) /\left[\pi \mathrm{r}_{\mathrm{G}}{ }^{2}(\mathrm{Z})\right] \text {. }
$$

The total incident power, $P_{\text {inc }}(Z)$, equals the total power transmitted from the GBL system, $P_{\text {trans }}$, multiplied by the atmospheric transmittance, $\mathrm{T}(\mathrm{Z})$ :

$$
P_{\text {inc }}(Z)=P_{\text {trans }} T(Z) \text {. }
$$

In turn, the transmittance, $T(Z)$, is determined by the power law:

$$
\mathrm{T}(\mathrm{Z})=\mathrm{T}(0)^{\mathrm{N}},
$$

where $\mathrm{T}(0)$ is the transmittance for a vertical beam and $\mathrm{N}$ is the atmospheric mass number or AMN. The value of $\mathrm{T}(0)$ is conservatively set at $80 \%$, while $\mathrm{N}$ is equal to the secant of the $\mathrm{AOZ}$.

\section{FIRING STRATEGY FOR DEBRIS REMOVAL}

The article of debris to be removed from orbit is assumed to be a section of aluminum plate having a 0.5 -cm thickness. This represents a type of material commonly used in the construction of space systems. The mass of the debris is treated as a variable in the simulations performed. It is proportional to the area of the debris surface receiving laser illumination above a threshold level to be specified below.

The debris orbit is assumed to be circular with an altitude between 350 and $450 \mathrm{~km}$. This range is of interest to the designers of the proposed US space station. For the sake of simplicity, the debris is also assumed to pass directly over the GBL site as it orbits the earth. This assumption is not overly restrictive. The induced orbital perturbations that are most effective in deorbiting debris occur when the debris $\mathrm{AOZ}$ is greater than zero.

The impulse and delta-velocity are imparted directly to the debris by way of laser-induced surface ablation and consequent impulse generation. The degree of ablation depends upon the absorbed intensity, which in turn depends upon the reflective properties of the debris surface and the orientation of that surface with respect to the beam.

The reflectivity of the surface depends upon its physical condition and the intensity of the incident radiation. It is reduced by the degrading effects of ultraviolet radiation and atomic oxygen, and is also affected by surface coatings applied during production and construction. In addition, all metals undergo abrupt decreases in reflectivity as the incident radiation intensity reaches a certain threshold value. This effect is associated with melting and vaporization of the surface, and frequently results in reflectivities approaching $50 \%$. This value is assumed throughout the remainder of this paper. ${ }^{21}$ 
For most ordinary materials, the onset of surface melting and vaporization occurs when the absorbed intensity is of the order of $10 \mathrm{~kW} / \mathrm{cm}^{2}$, assuming sufficiently long irradiation time. ${ }^{22}$ From the absorbed fluence (energy/area) at the surface, it is possible to estimate the resulting generated impulse-per-unit-area. Laboratory experiments with aluminum targets and wavelengths near 1 micron show that the ratio of impulse-per-unit-area to absorbed fluence is about 1 dyne/watt. ${ }^{\dagger}$ This value is also consistent with first-principles models ${ }^{\ddagger}$ and is assumed in this paper. ${ }^{23}$

The effect of debris rotation is to cause the laser-induced impulse vector, which is always normal to the debris surface, to rotate as well. In the simulations performed, this was taken into account by time-averaging the impulse vector. As a result, the average impulse parallel to the beam is one-half the peak value occurring when the surface is normal to the beam, and the average impulse perpendicular to the beam is zero. Therefore, the time-averaged impulse vector is parallel to the laser beam itself.

The laser firing strategy allows debris to be irradiated for the longest possible time, and is illustrated in Figure 3 . The laser is first fired when the debris is approaching the GBL site from the west and the $\mathrm{AOZ}$ is no greater than about 60 degrees. The laser continues to fire until the debris passes over the laser site. The total irradiation time available is therefore about 80 to 100 seconds for the altitude range assumed here.

The time-averaged delta-velocity imparted to the debris is paraliel to the laser beam, as is the induced impulse. It has a component opposite to the debris velocity vector, as well as one normal to that vector. The effects on orbital parameters can be determined using conventional perturbation theory. The semi-major axis and the eccentricity are affected in such a way that the orbit becomes elliptical with its apogee over the GBL site and its perigee on the side of the earth opposite the site. 1,24

\section{DETERMINATION OF THE PERTURBATIVE FORCE}

The absorbed intensity distribution is modeled as a discontinuous function of the threshold absorption coefficient, taken to be $50 \%$, and the incident laser intensity. Above the threshold it equals the product of these quantities, while below the threshold it is relatively small and is taken to be zero. This is illustrated in Figure 2 . The absorbed intensity distribution can be expressed in terms of the radius at threshold, $\mathrm{r}^{*}(\mathrm{Z})$, as follows:

$$
I_{a b s}(Z, r)= \begin{cases}C_{a b s} I_{\text {inc }}(Z, r), & r \leq r^{*}(Z) ; \\ 0, & r>r^{*}(Z) .\end{cases}
$$

For a given $\mathrm{AOZ}$, the value of $\mathrm{r}^{*}(\mathrm{Z})$ is defined in terms of the threshold absorption coefficient and the absorbed intensity threshold, with the latter taken to be $10 \mathrm{~kW} / \mathrm{cm}^{2}$ :

$$
\mathrm{I}_{\mathrm{abs}}{ }^{*}=\mathrm{C}_{\mathrm{abs}} \mathrm{I}_{\mathrm{inc}}\left(\mathrm{Z}, \mathrm{r}^{*}(\mathrm{Z})\right) \text {. }
$$

The impulse-per-unit-area, equal to the product of the laser-induced pressure and the laser irradiation time, can be empirically related to the absorbed fluence:

$$
\mathrm{p}(\mathrm{Z}, \mathrm{r}) \Delta \mathrm{t}=\mathrm{C}_{\mathrm{imp}} \Delta \Phi_{\mathrm{abs}}(\mathrm{Z}, \mathrm{r}) .
$$

Here $\mathrm{C}_{\mathrm{imp}}$ is the impulse coupling coefficient and is taken to be 1 dyne/watt. The absorbed fluence, in turn, equals the product of the absorbed intensity and the irradiation time:

$$
\Delta \Phi_{\mathrm{abs}}(\mathrm{Z}, \mathrm{r})=\mathrm{I}_{\mathrm{abs}}(\mathrm{Z}, \mathrm{r}) \Delta \mathrm{t} .
$$

$\dagger$ J. Beraune, private communication, Phillips Laboratory, KAFB, Albuquerque, NM.

¥ R.J. Lawrence, Sandia National Laboratories, personal communication. 
Combining these results, the laser-induced pressure is found to be:

$$
p(Z, r)=C_{i m p} I_{a b s}(Z, r) .
$$

The peak value of the laser-induced force occurs when the beam is normal to the debris surface. It equals the integral of the induced pressure over all parts of the debris surface where the intensity is at or above the threshold. The peak force on the debris can be expressed as:

$$
F_{\text {peak }}(Z)=C_{\text {imp }} C_{a b s} P_{\text {ind }}(Z) f_{D}^{*}(Z) .
$$

The area fraction, $\mathrm{f}_{\mathrm{D}}^{*}(\mathrm{Z})$, is a scaling factor obtained in performing the surface integral and equals:

$$
f_{D}^{*}(Z)=1-\exp \left\{-\left[r_{D}^{*}(Z) / r_{G}(Z)\right]^{2}\right\}
$$

where $r_{D}^{*}(z)$ is the smaller of $r^{*}(Z)$ and $r_{D}$ :

$$
\mathbf{r}_{D}^{*}(Z)= \begin{cases}\mathbf{r}^{*}(Z), & \mathbf{r}^{*}(Z) \leq r_{D} \\ r_{D}, & \mathbf{r}^{*}(Z)>r_{D}\end{cases}
$$

The average induced force, which is parallel to the laser beam, is then calculated as follows:

$$
F_{\text {ave }}(Z)=C_{\text {rot }} F_{\text {peak }}(Z),
$$

where $\mathrm{C}_{\text {rot }}$ is the rotation coefficient, and is assumed to be $50 \%$. The vector components of the perturbative acceleration can now be determined, given the mass of the debris and the laser beam angle-off-zenith (AOZ). These components are used to calculate the resulting orbital parameter perturbations, which accumulate with time as the debris approaches the GBL site from the west. ${ }^{24}$

\section{RESULTS AND CONCLUSIONS}

Computer modeling was used to simulate the processes involved in laser debris removal with a GBL system. The bulk of the results obtained are summarized in Figure 4. As expected, debris removal capability is greatest for debris at lower altitudes. A $0.9-\mathrm{kg}$ article of debris can be deorbited from $300 \mathrm{~km}$ altitude after a single pass over the laser site, and the mass increases to over $4 \mathrm{~kg}$ when five passes are allowed. In contrast, for orbital altitudes of $475 \mathrm{~km}$, the mass is just over $0.01 \mathrm{~kg}$ for one pass and about $0.08 \mathrm{~kg}$ for 5 passes. To deorbit $1-\mathrm{kg}$ debris from altitudes of about $500 \mathrm{~km}$ and higher requires more than $5 \mathrm{MW}$ of laser power output.

The altitude range of 350 to $450 \mathrm{~km}$ is of particular interest to designers of the US space station, and has been emphasized in Figure 4. With one pass over the GBL site, the maximum removable mass is almost $0.5 \mathrm{~kg}$ at the lower altitude and is about $0.06 \mathrm{~kg}$ at the higher altitude. With five passes the mass is about $2.3 \mathrm{~kg}$ at the lower altitude and almost $0.3 \mathrm{~kg}$ at the higher one.

Simulation results yield other conclusions, as well. Laser ablation of debris at space station altitudes becomes feasible when the laser output power is just over $2 \mathrm{MW}$. This represents a threshold for removal of debris with a GBL, assuming the wavelength is $1733 \mathrm{~nm}$ and the mirror diameter is $10 \mathrm{~m}$. Using a shorter wavelength would require less power, while using a smaller mirror would require more power.

The same laser to be used for ablating debris can also be used for detecting and tracking debris. If the beam director is sufficiently agile, then the beam can be broadened to illuminate debris without inducing surface ablation and impulse. The 
beam can then be refocused onto a specific article of debris whose position has been accurately determined, and the resulting higher intensity can be used to impart delta-velocity.

In conclusion, utilizing a GBL to remove debris from LEO is technically feasible and practical. It does not involve launching any systems or components into orbit. This increases overall cost effectiveness and avoids the problem of adding launch-related debris to the LEO environment. The method requires using a laser source and a beam director located on the earth's surface. This means that current and near-term technologies will be sufficient for the construction and operation of the GBL system.

\section{REMAINING ISSUES}

Several issues relating to GBL removal of artificial space debris have not yet been addressed. One important question is whether sufficient impulse can be generated without causing debris breakup. Naturally this depends upon the material makeup and general condition of the debris itself. Judging from the magnitudes of the average pressures observed in system simulations, it is reasonable to conclude that debris breakup during laser irradiation is unlikely in nearly all cases.

A related issue is the production of additional debris from ablated surface material. Laboratory tests show that these secondaries have sizes of the order of one micron. Many of them will deorbit very quickly because of their high drag-toweight ratios and their highly elliptical orbits. Those that remain in orbit can be dealt with by using passive shields on active assets. It is of interest to note that, if all existing debris were reduced to micron-sized particles, the total flux would be negligible in comparison to the existing flux of micrometeors. 1,23

An additional issue is related to the requirement that the laser beam be held on the debris continuously for nearly 100 seconds. The beam director must be rapidly and accurately steered or the laser-induced impulse will at best be intermittent. For space station altitudes, the beam director must be steered at a rate of about one milliradian per second with a pointing accuracy of under one microradian. It is estimated that these capabilities are within the reach of near-term technologies. In fact, a demonstration of these capabilities has been scheduled using the $3.5-\mathrm{m}$ mirror at the USAF Phillips Laboratory Starfire Optical Range.

A very serious issue is the need to prevent the laser beam from inadvertently irradiating an orbiting system that is still active or that is sensitive in nature. For US satellites such events can be avoided by utilizing an existing laser clearinghouse. Its purpose is to grant approval for laser beaming experiments, after verifying that no undesirable results will occur. As far as foreign satellites are concerned, there are existing treaties that prohibit laser irradiation of satellites belonging to cosigning nations. Protocols for approval must be complied with, even though the probability of an incident is quite small, so as to avoid international complications.

\section{ACKNOWLEDGMENTS}

This work was performed for the FALCON Program at Sandia National Laboratories in Albuquerque, NM under DOE contract DE-AC04-94AL85000. The author wishes to thank Ronald J. Lipinski and William J. Tedeschi for guidance and helpful comments.

\section{REFERENCES}

1. N. L. Johnson, D. S. McKnight, Artificial Space Debris, Orbit Book Company (1987).

2. T. Logsdon, "The Orbital Environment," Fundamentals of Orbital Mechanics, AIAA Prof. Study Series, Washington, DC (January 15-17, 1992).

3. B. Wood-Kaczmar, "The Junkyard in the Sky," New Scientist, 37 (October 13, 1990).

4. H. Gavaghan, "Catastrophic Collisions in Orbit Could Stop Space Research," New Scientist, 27 (October 21, 1989).

5. P. Hoversten, "Flying Defensively," Discover, 28 (April, 1990).

6. D. J. Frederick, "Orbiting Garbage," Ad Astra, $\underline{38}$ (November, 1991). 
7. "Sweeping Up Space Junk," Discover, 11 (January, 1992).

8. "Trashing Space," Science and the Citizen, Scientific American, 14 (August, 1987).

9. D. J. Kessler, "Orbital Debris Environment for Spacecraft in Low Earth Orbit," J. Spacecraft, 28, No. 3, 347 (MayJune, 1991).

10. D. J. Kessler, "Current Orbital Debris Environment," in Orbital Debris from Upper-Stage Breakup, J. P. Loftus, Jr. (ed.), Progress in Astronautics and Aeronautics, 121 (1989).

11. R. Cowen, "LDEF Maps Orbiting Junk," Science News, 139, No. 24, 381 (June 15, 1991).

12. C. Butner, C. Gartrell, GRC Orbital Debris Mitigation Systems : Innovative Approaches to Solving Future Problems, AIAA Space Programs and Tech. Conf., Huntsville, AL. (March 24-27, 1992).

13. Debris Collision Warning Sensors (DCWS), briefing by Lockheed Engineering and Sciences, Co. to NASA/JSC.

14. H. Gavaghan, "Lasers Blast a Path Through Orbiting Litter," New Scientist (October 20, 1990).

15. J. D. Metzger, R. J. LeClaire, S. D. Howe, K. C. Burgin, "Nuclear Powered Space Debris Sweeper," J. Propulsion, 5, No. 5 (September-October, 1989).

16. P. M. Sforza, "Laser Systems for Spacecraft Hull Protection," 42 nd Congress of the International Astronautical Federation, Montreal, Canada (October 5-11, 1991).

17. W. J. Alford, G. N. Hays, "Measured Laser Parameters for Reactor-Pumped He/Ar/Xe and Ar/Xe Lasers," J. Appl. Phys., 65, 3760-3766 (1988).

18. G. A. Hebner, G. N. Hays, "Fission-fragment-excited lasing at $585.3 \mathrm{~nm}$ in $\mathrm{He} / \mathrm{Ne} / \mathrm{Ar}$ gas mixtures," Appl. Phys. Lett., 57, (21), 2175 (Nov. 19, 1990).

19. T. K. Tyson, Principles of Adaptive Optics, Academic Press, Inc. (1991).

20. C. S. Powell, "Mirroring the Cosmos," Scientific American (November, 1991).

21. T. E. Zavecz, M. A. Saifi, "Metal Reflectivity Under High-Intensity Optical Radiation," Appl. Phys. Lett., 26, No. 4 (1975).

22. N. Bloemberger, "Pulsed Laser Interactions with Condensed Matter," in Beam-Solid Interactions and Phase Transitions, H. Jurz, G. L. Olson, J. M. Poate (ed.) (1986).

23. E. M. Breinan, B. H. Kear, C. M. Banas, "Processing Materials with Lasers," Physics Today, 44 (November, 1976).

24. R. R. Bate, D. D. Mueller, J. E. White, Fundamentals of Astrodynamics, Dover Publications, Inc., New York (1971). 
Figure 1. Primary subsystems of a ground-based reactor-pumped laser used for debris removal

GBL - high-power, ground-based reactor-pumped laser

SBD - steerable beam director with deformable mirror

AOU - adaptive-optics unit to sense turbulence and generate control signals

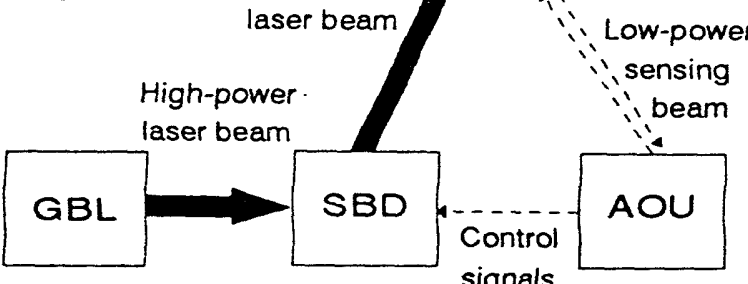

Figure 3. A 5-MW ground-based RPL can deorbit debris via laser-induced impulse generation.

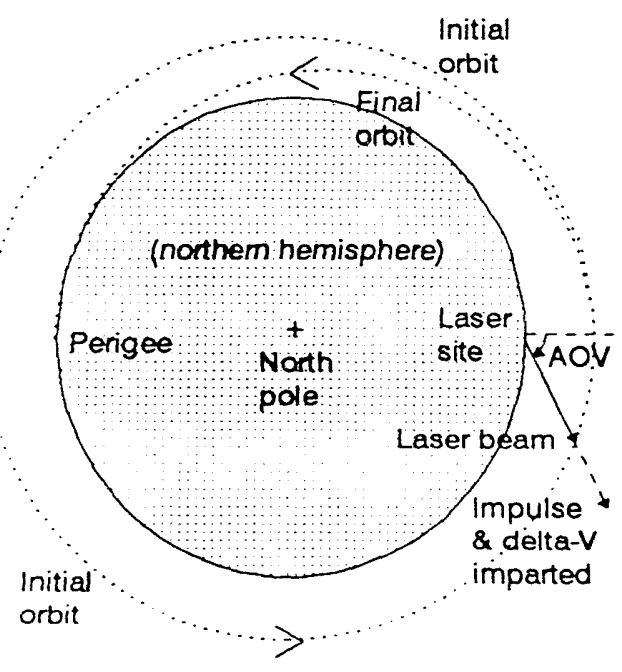

Debris "fired" upon on approach from west

Semi-major axis and eccentricity decreased

Perigee or re-entry on opposite side of earth

Tracking and liability minimized
Figure 2. Variation of incident and absorbed intensity distributions over width of beam.

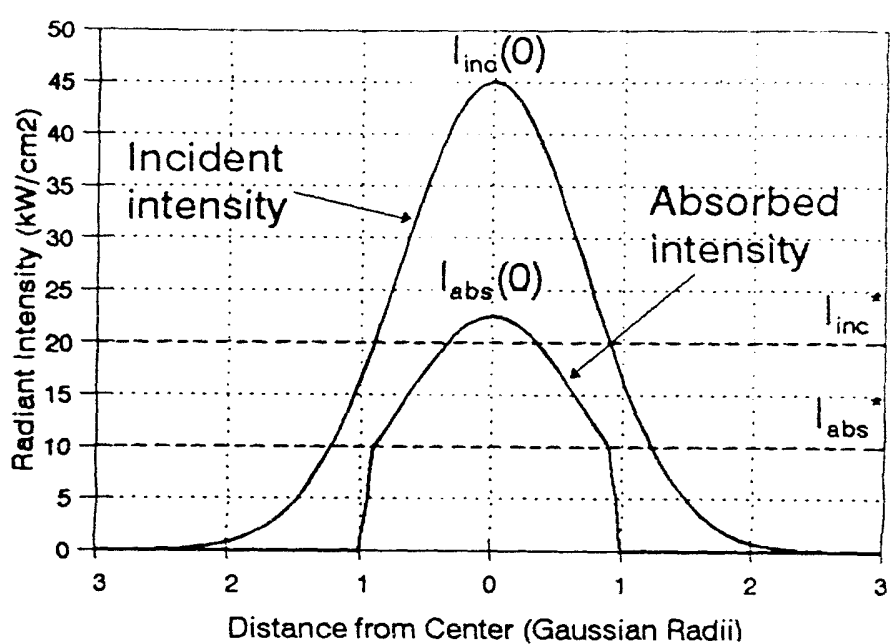

Figure 4. Maximum debris mass removable with proposed ground-based laser system

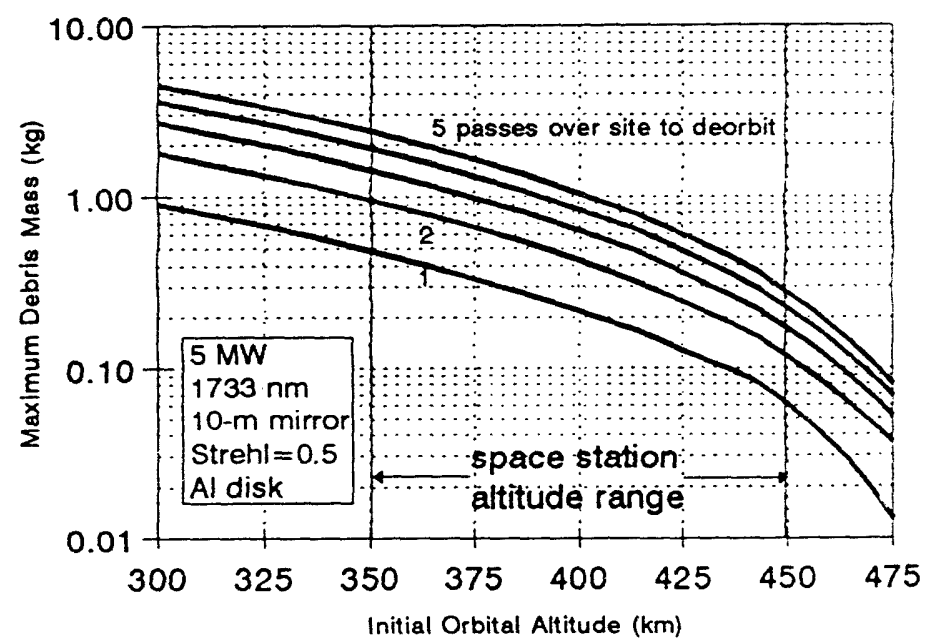




\section{A reactor-pumped GBL can remove space space from space station altitudes}

Feasible, practical, cost effective, no launches, no orbital mirror

Reduces tracking problems and liability issues

Delta-V produced by laser ablation, break-up of debris unlikely, micron-sized ejecta produced

Requires just over $2 \mathrm{MW}$ with a 10-m mirror and a waveiength of $1733 \mathrm{~nm}$

Can deorbit masses of the order of $1 \mathrm{~kg}$ and greater

Can transfer larger debris to alternate orbits

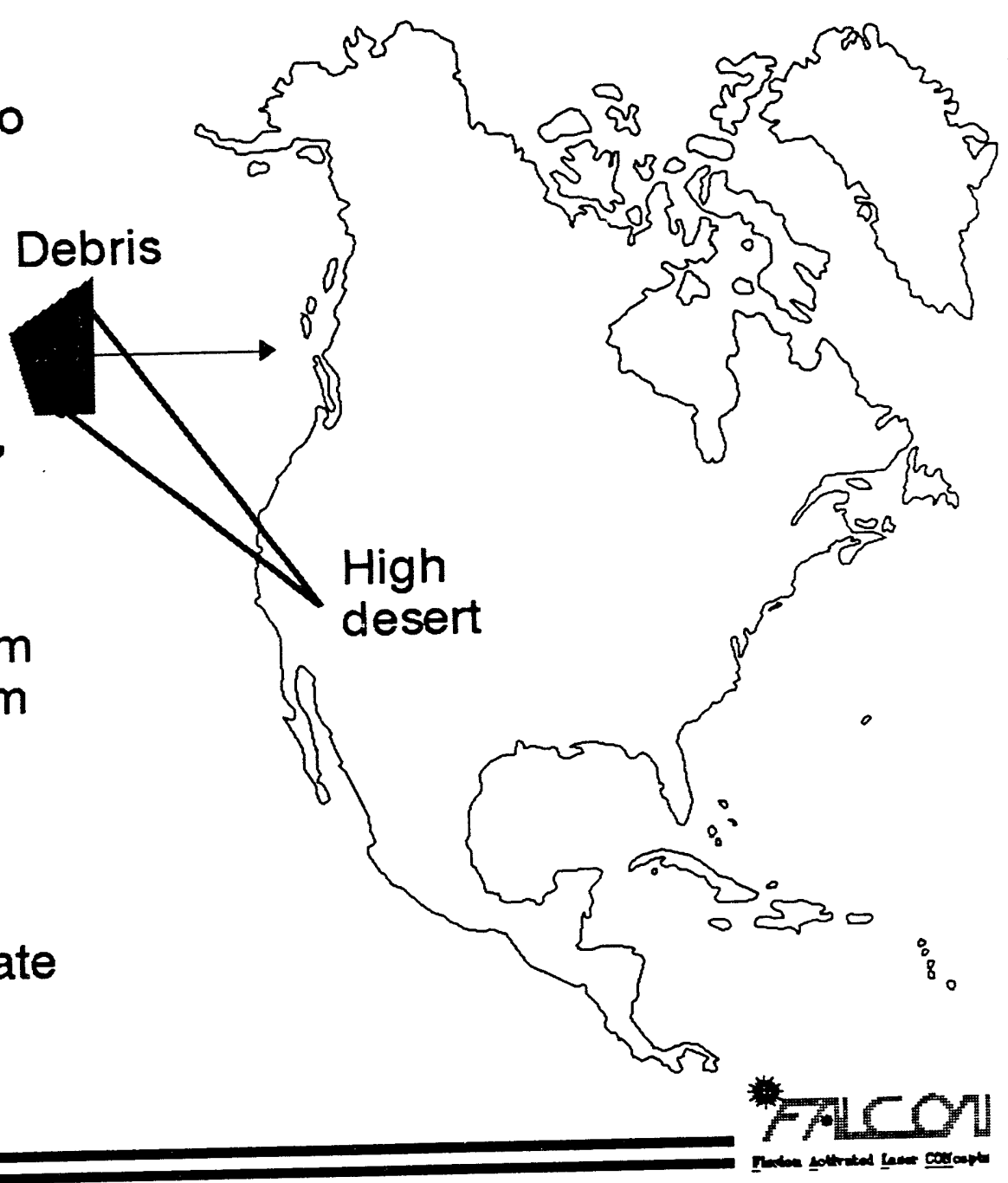




\section{Time interval for laser to fire at debris
varies with altitude and angle-off-zenith}

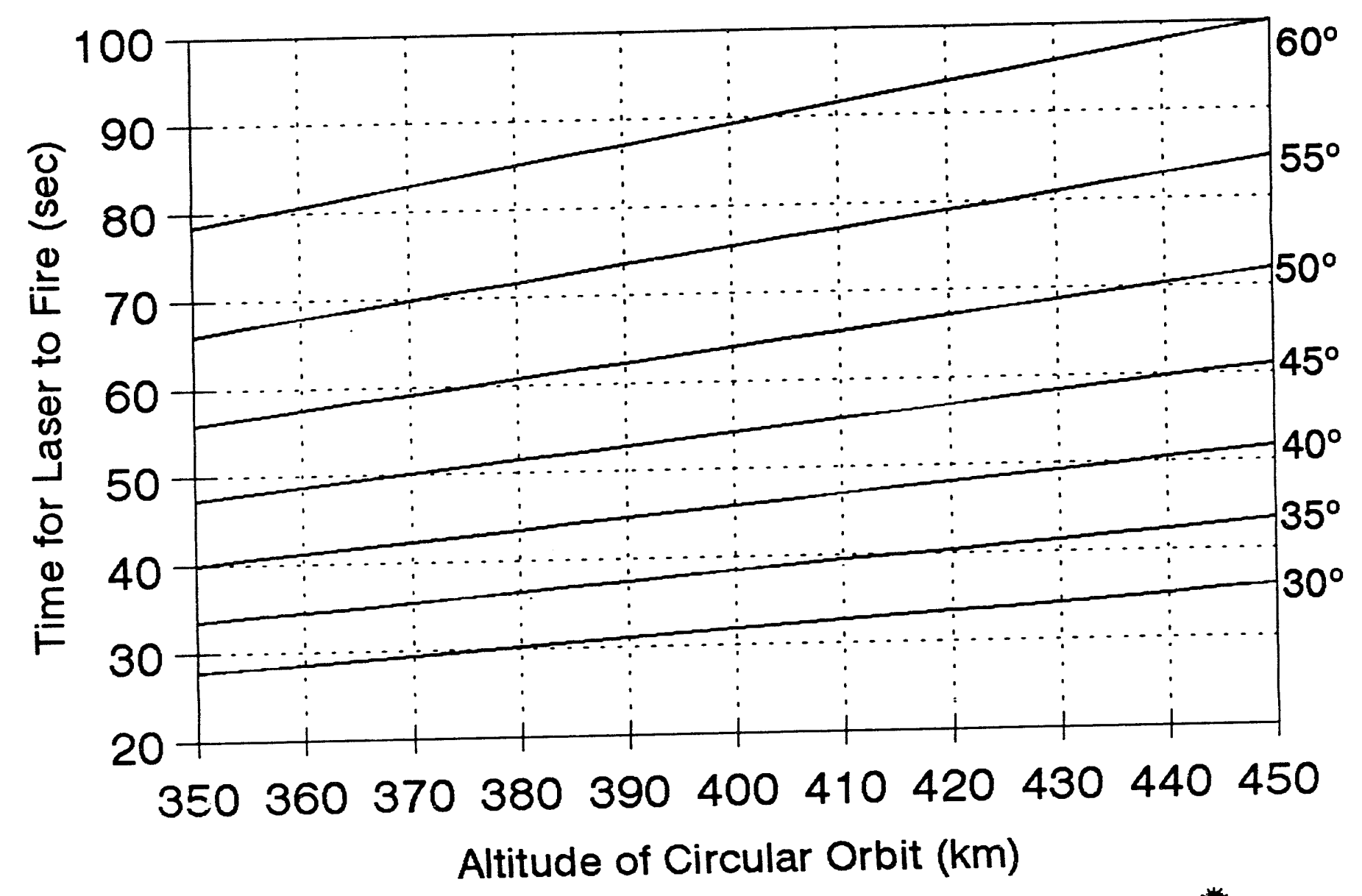

Altitude of Circular Orbit (km) 


\begin{tabular}{|c|c|c|}
\hline Lasing Atom & Wavelength $(\mathrm{nm})$ & Intrinsic Efficiency \\
\hline xenon & 3370 & $>0.1 \%$ \\
\hline xenon & 2650 & $>0.1 \%$ \\
\hline xenon & 2630 & $>0.1 \%$ \\
\hline xenon & 2032 & $2.0 \%$ \\
\hline xenon & 1733 & $2.5 \%$ \\
\hline argon & 1792 & $1.4 \%$ \\
\hline argon & 1271 & $1.1 \%$ \\
\hline neon & 725 & $0.10 \%$ \\
\hline neon & 703 & $0.05 \%$ \\
\hline WLENGTH2.Сн3 & 585 & $<0.1 \%$ \\
\hline
\end{tabular}




\section{Incident intensity of corrected beam has} nearly-Gaussian distribution

$$
I_{\text {inc }}(z, r)=I_{\text {inc }}(z, 0) \exp \left\{-\left[r / r_{G}(z)\right]^{2}\right\}
$$

$\mathrm{I}_{\text {inc }}(\mathrm{z}, 0)=\mathrm{P}_{\text {inc }}(\mathrm{z}) / \mathrm{A}_{\mathrm{G}}(\mathrm{z}) \quad \mathrm{P}_{\text {inc }}(\mathrm{z})=\mathrm{P}_{\text {trans }} \mathrm{T}(\mathrm{z})$

$$
\begin{aligned}
& A_{G}(z)=\pi r_{G}^{2}(z) \\
& T(z)=T(0)^{\sec (z)}
\end{aligned} \quad r_{G}(z)=\frac{2 \lambda_{\text {trans }} R_{\text {deb }}(z)}{\pi D_{\text {mirror }} \sqrt{S}}
$$




\section{High power lasers can generate delta-V by laser-induced surface ablation}

Impulse coupling coefficient versus absorbed fluence

Aluminum sample, CHROMA laser, 1.054 microns

Absorbed intensity of at least $10 \mathrm{~kW} / \mathrm{cm} 2$ (threshold)

Absorbed fluence of at least $100 \mathrm{~J} / \mathrm{cm} 2$ (threshold)

Impulse coupling coefficient of about 1 dyne/watt

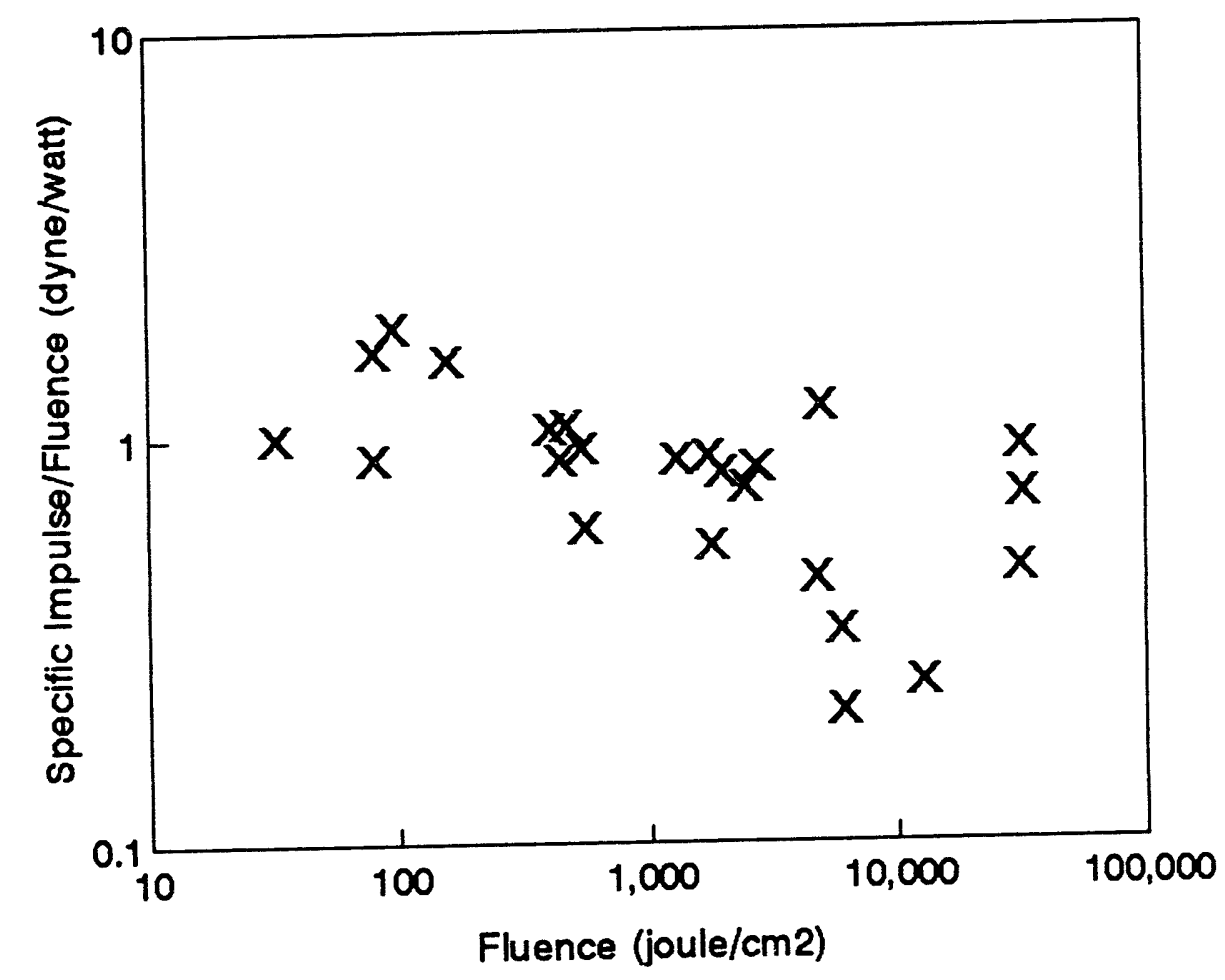

"An Effective Properties Model for Pulsed Radiation Interactions"

R.J. Lawrence, Sandia National Labs 


\section{Laser-induced ablation of rotating article of debris produces rotating force vector

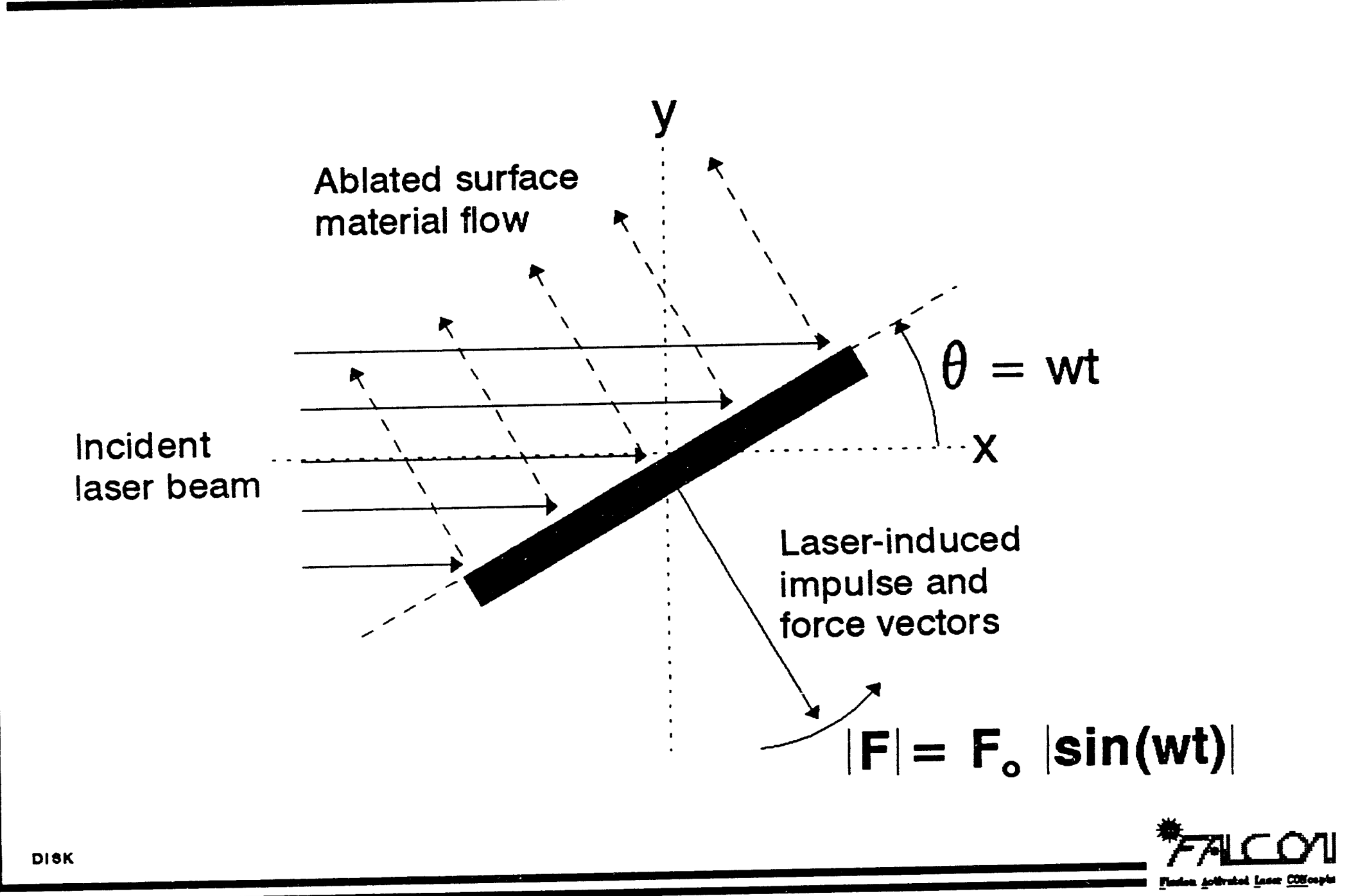




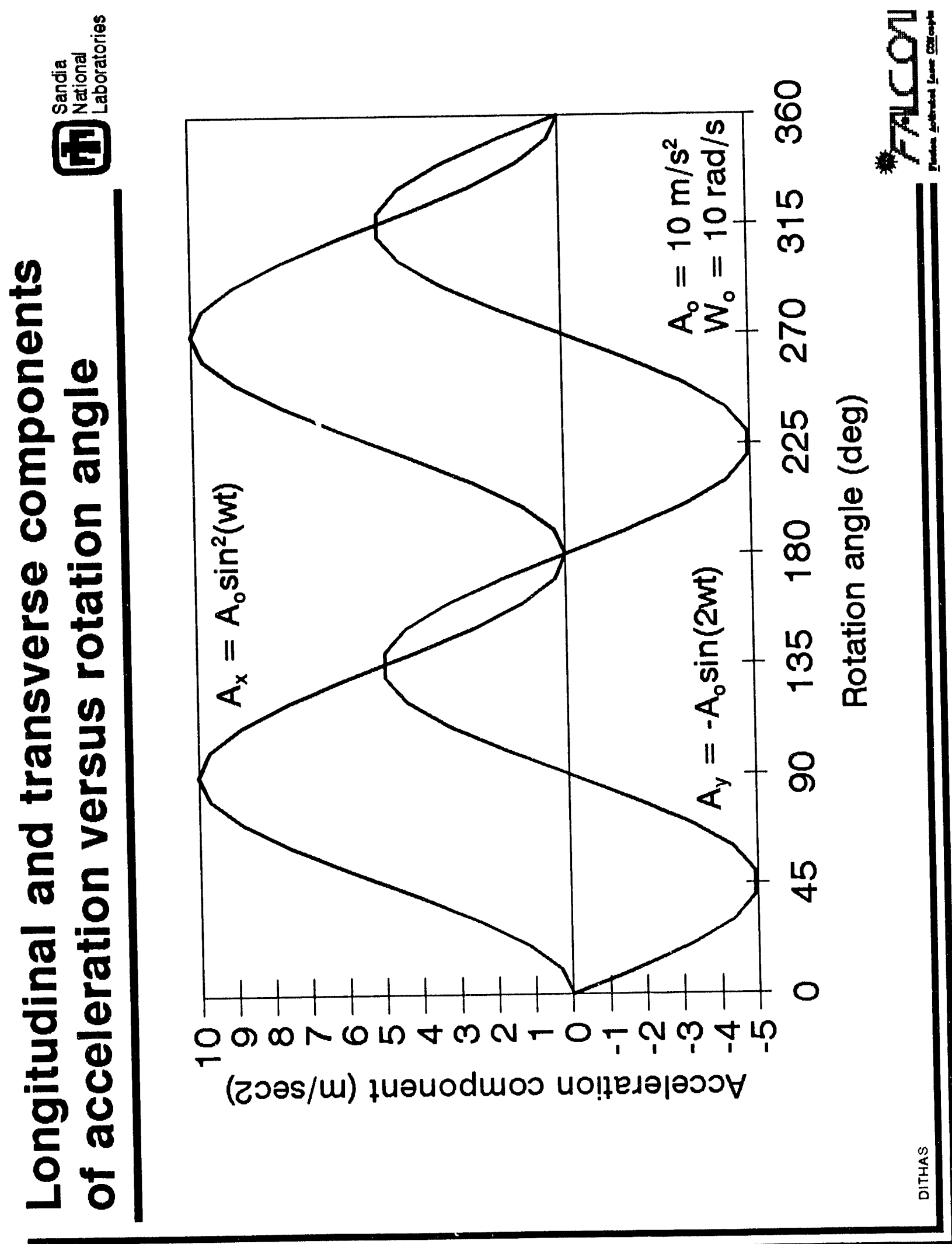




\section{Longitudinal and transverse components of displacement versus rotation angie}

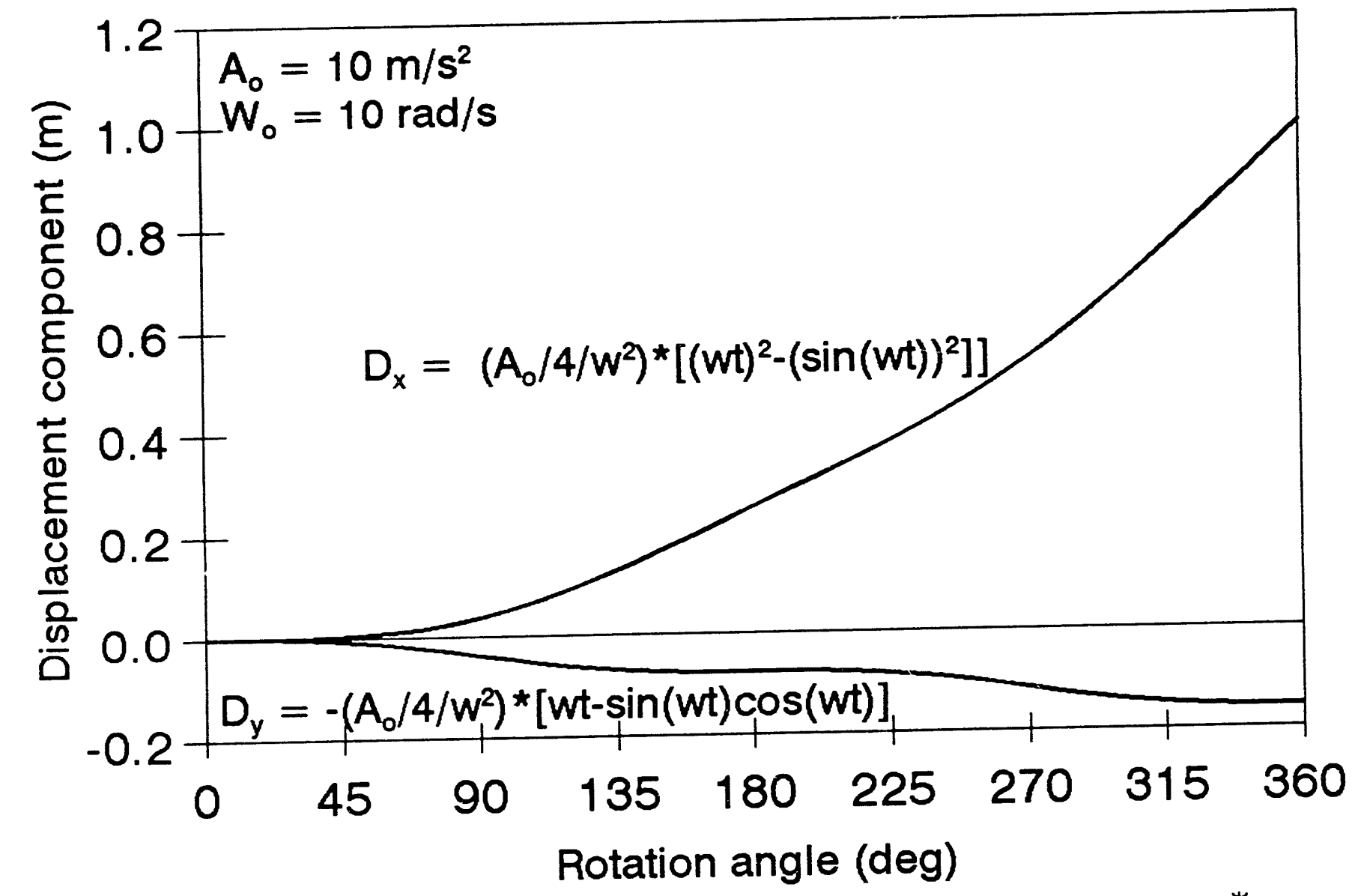




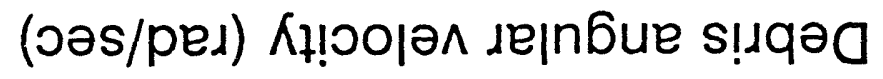

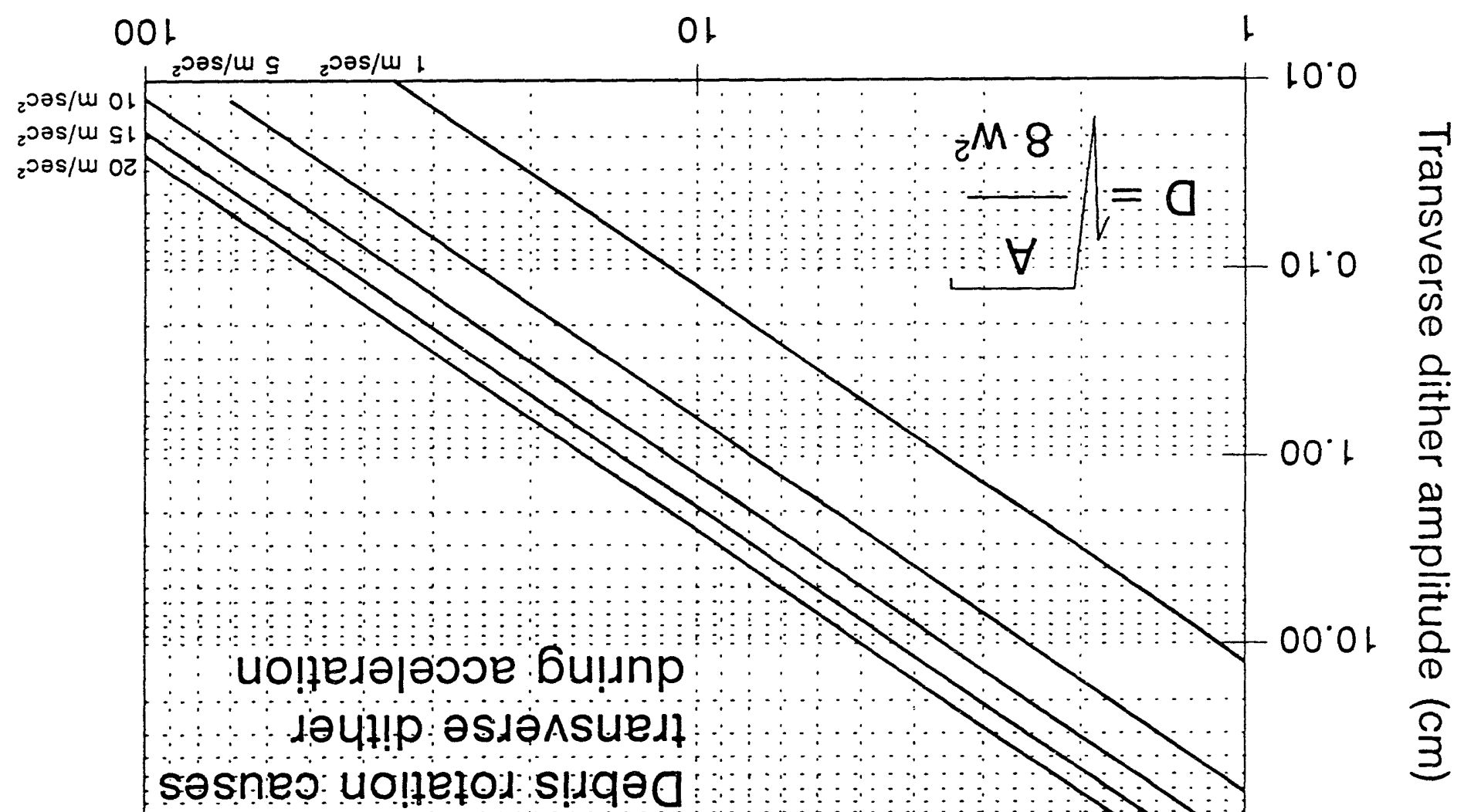




\section{A 5-MW, 1733-nm reactor-pumped ground-based laser can deorbit debris from space station altitudes}

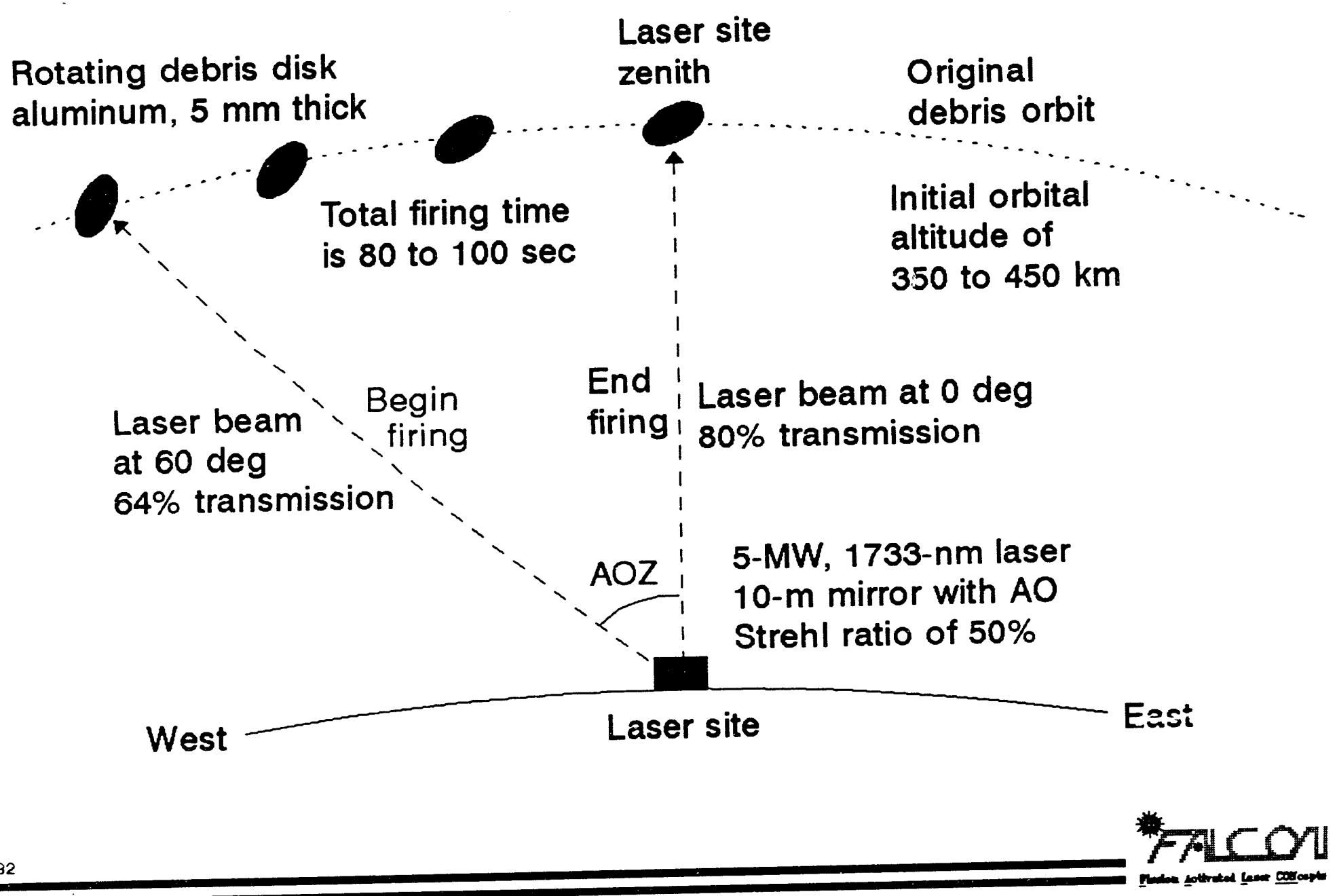




\section{A ground-based laser with 2+ MW can ablate debris at space station altitudes}

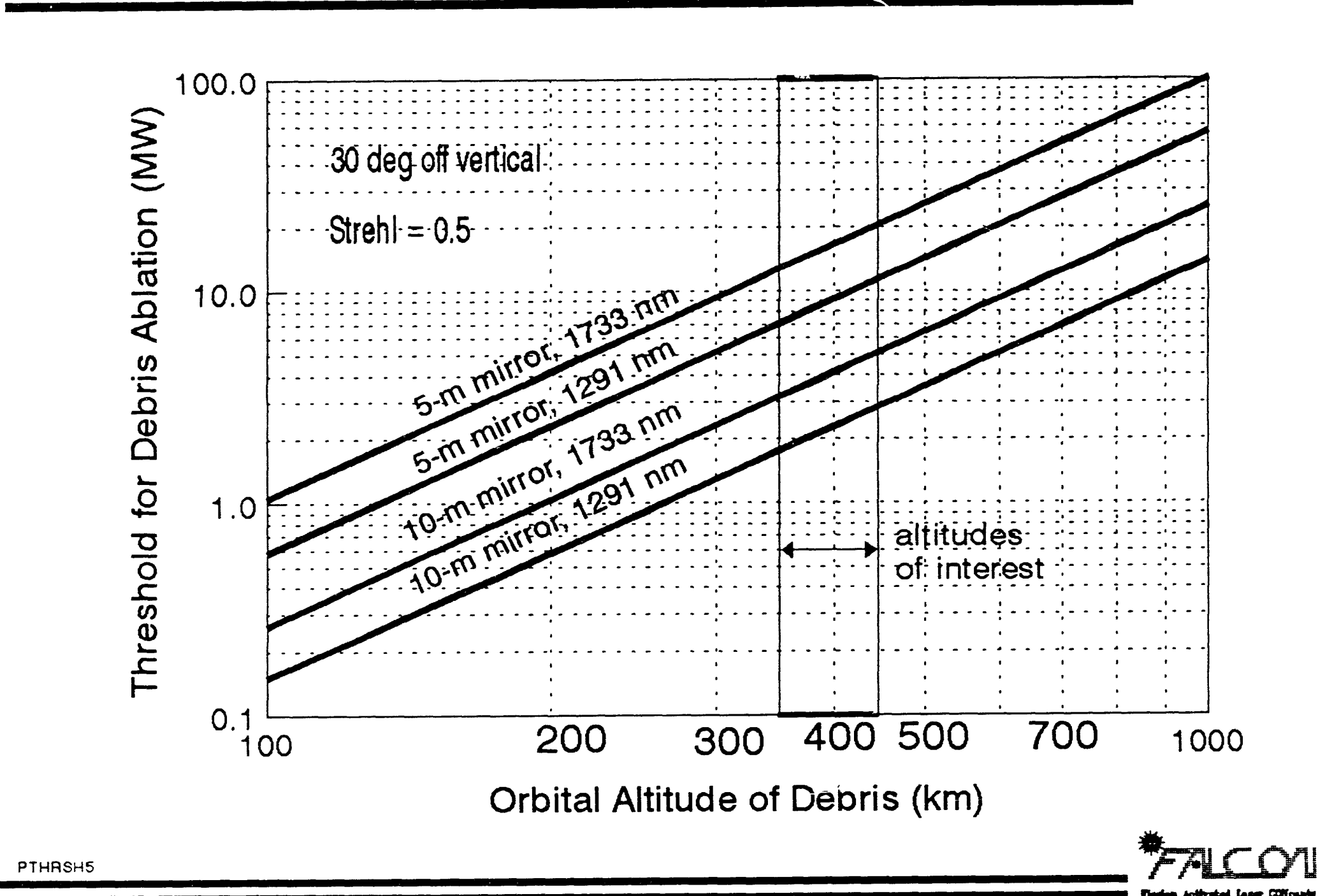




\section{A GBL with 10-MW output can deorbit debris from altitudes above $500 \mathrm{~km}$}

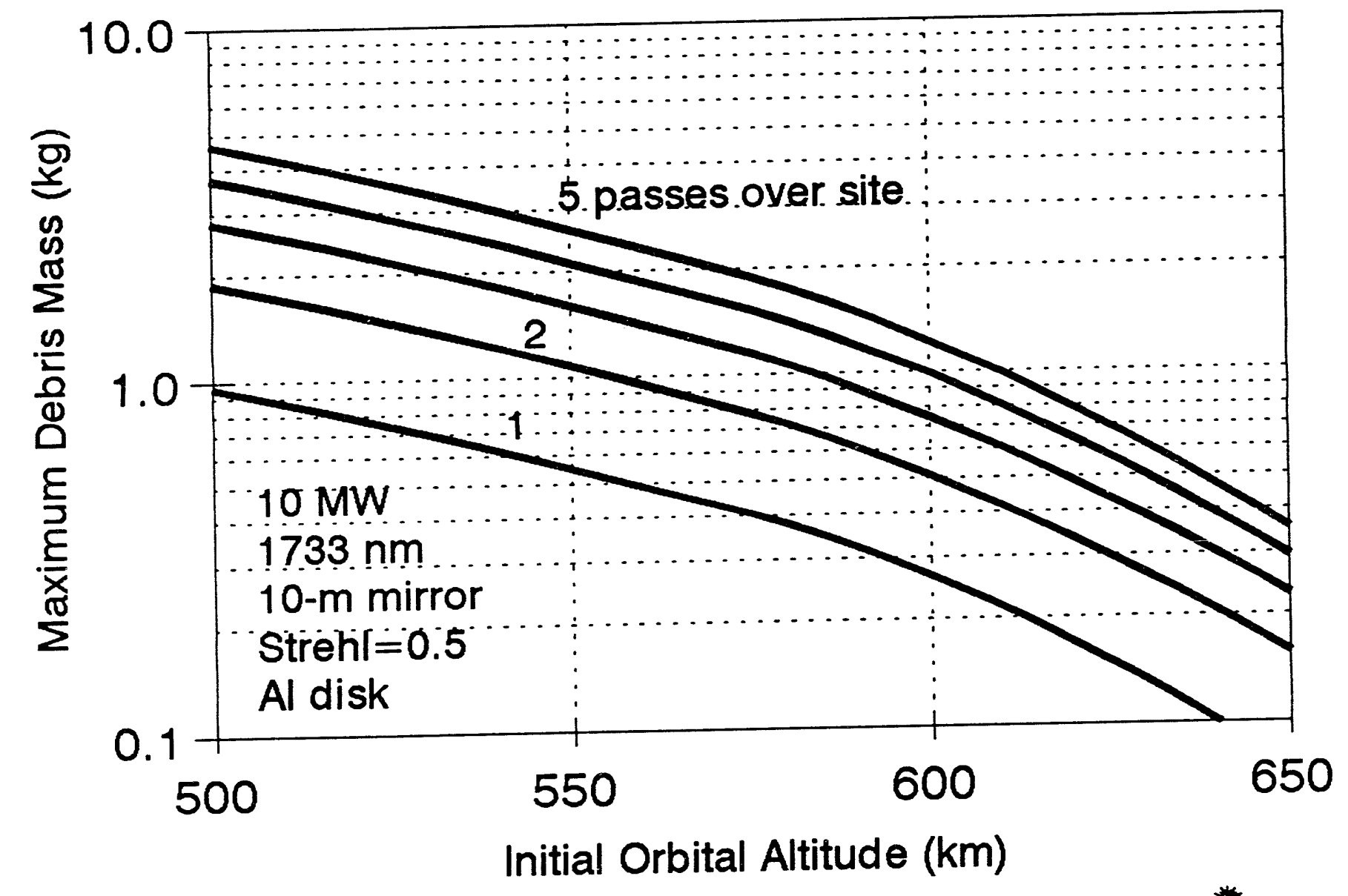



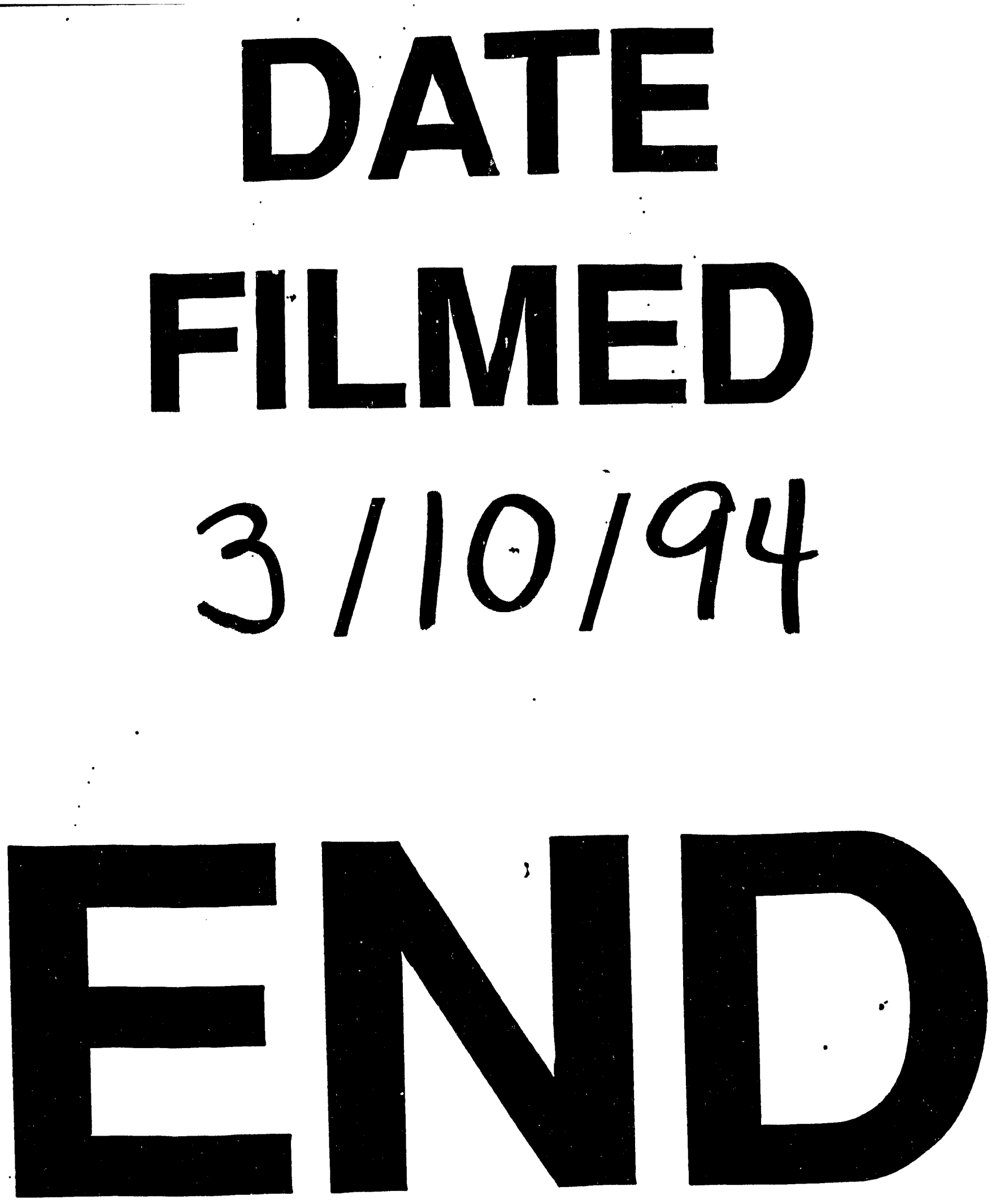
